\title{
A model for stochastic prediction of track support stiffness
}

Louis Le Pen, David Milne, Geoff Watson, John Harkness, William Powrie

Infrastructure Research Group, Faculty of Engineering and the Environment, University of Southampton, Southampton, SO17 1BJ, United Kingdom.

Corresponding Author: Louis Le Pen: ॥p@soton.ac.uk

This untypeset authors version of this article was accepted for publication by the Journal of Rail and Rapid Transit on 10 March 2019. A data set for the article is available from the University of Southampton's online repository with the DOI: https://doi.org/10.5258/SOTON/D0844

\section{Abstract}

As well as guiding the train, one of the key aims of a railway track system is to provide support to the train at the wheel-rail interface that is of near-uniform compliance. Of the various components that make up this compliance, the contribution of the trackbed (ballast and subgrade) is the most difficult to understand and control. This paper presents data from field measurements of track support system stiffness for a continuous run of 209 sleepers on a high speed ballasted railway. The data indicate a level of variability, even on a highly engineered and well-maintained route. Statistical analysis of the data is used to demonstrate the dependence of the trackbed modulus at an individual sleeper on the modulus of the sleeper immediately preceding it, and that in statistical terms the effect of sleepers further away is due to correlation between the intermediate sleepers. An optimum trackbed stiffness, close to the overall mean, at which the standard deviation is a minimum is demonstrated for a particular site. As the trackbed stiffness moves away from this optimum value, the likely variation from sleeper to sleeper increases. A framework for implementing a stochastic approach to predicting the variation in track support stiffness from one sleeper to another, based on a Markov model and appropriate probability distribution functions, is then proposed. This framework may be used for the quantitative comparison of different sites, and to simulating plausible values of track stiffness in vehicle-track interaction analysis.

\section{Introduction}

Increased demand for rail travel means that existing railways are being more intensively used by longer, faster, more frequent and heavier trains. Meeting the associated performance requirements, requires an improved understanding of the mechanisms of track geometry deterioration and methods of track design, specification and installation to minimise maintenance needs.

Ballasted railway track design generally assumes a uniform support at the wheel-rail interface. This comes from a number of compliant components - rails, fixings, railpads, ballast, subballast and subgrade - in series. Of these, the support provided below the level of the sleeper (the trackbed) is the most difficult to control owing to natural variability in the underlying ground and the sleeper to ballast interface ${ }^{[1]}$. The changes that occur with repeated loading (differential settlement and soil stress history dependent behaviour) are further complication.

The track support stiffness governs stress transfer from the wheel-rail interface into the trackbed. A lower support system stiffness spreads the deflection bowl along a greater length of track. This reduces peak trackbed stresses, at the expense of increased rail bending ${ }^{[2,3]}$. 
Railway specifications attempt to achieve uniform support from the trackbed by different means. UIC $719^{[4]}$ requires a minimum $E_{v 2}$ value at the prepared subgrade for new track of $80 \mathrm{MPa}$ (determined from the second unload/reload loop in a plate bearing test). UK standards ${ }^{[5]}$ include the effect of the ballast by specifying a minimum sleeper spring stiffness. However, measurements show that the movement ranges and hence support stiffnesses on operational track vary considerably between nearby sleepers, even on highly engineered routes (e.g. ${ }^{[6,7]}$ ).

Variability in the track support stiffness gives rise to dynamic train/track interactions and increments of dynamic load that contribute to deterioration of track geometry. This can be modelled in vehicletrack interaction (VTI) analyses, but there are relatively few data with which to characterise the variation in track support system stiffness expected on notionally uniform track (i.e. in the absence of features such as hard or soft sub-structures, crossings and transitions). The aim of this paper is to develop a quantitative, statistical understanding of the inherent variability in track support system stiffness on plain line, by:

- reporting a set of acceleration measurements on 209 adjacent sleepers as trains pass, and applying a newly-developed method to determine the support stiffness

- comparing candidate probability distributions, fitted to the data using a banding technique, to capture the variation in distribution of adjacent sleeper support stiffness

- using the data to develop a probabilistic framework based on a Markov Chain, utilising a transition array developed from the field measurements and selected distribution functions.

- extending the transition array for continuous conditional probability distributions within prescribed rules of system behaviour

- discussing the applicability of the methods developed and their potential uses.

\section{Background}

In recent decades, an improving understanding of the role of track stiffness and its spatial variability have led to it being identified as the key parameter in the performance of ballasted railway track (e.g. $\left.{ }^{[8-12)}\right)$. At transitions, abrupt changes in stiffness can lead to the development of track faults (e.g. ${ }^{[13-21]}$ ). However, track faults also develop along plain line and variations in track stiffness are surprisingly common, even where there is no obvious cause.

Track system support stiffness has been shown to influence settlement rates and track geometry (e.g. ${ }^{[8,22,23]}$ ). To capture this in predictive tools able to model repeated train/track interaction, relationships are needed to link the development of permanent settlement with the stiffness and applied load/stress. However, current track settlement equations are empirical and do not account for all the relevant variables. Many are log-linear relationships that estimate settlement based on the number of loading cycles and either the strain or the load on the first cycle ${ }^{[24,25]}$. Most show that settlement occurs at a reducing rate with increasing number of cycles, but may not allow for varying loading and tend to apply solely to the conditions under which they were determined.

Some more general settlement relationships do include track stiffness and/or stress in their formulation. Guerin ${ }^{[26]}$ proposed that the settlement per load cycle was calculated as a proportion of the recoverable range of movement, which in turn depends on both the stiffness and the load. Sato ${ }^{[27]}$ proposed two relationships, one for track settlement and one for the development of track irregularity; both have the potential to capture a range of elements of track behaviour including variations in load. However, these more general methods require further validation. 
Oscarsson ${ }^{[9 \& 10]}$ investigated the performance of railway track in a numerical vehicle/track interaction model incorporating stochastic properties for the behaviour of the track structure. Gaussian distributions were used to describe the railpad stiffness, ballast stiffness, ballast subgrade mass and sleeper spacing, and Monte Carlo simulations were carried out to investigate stochastic variations in these parameters on the maximum wheel/rail contact force, displacement and acceleration. The approach was developed by Nielsen and Oscarsson ${ }^{[28]}$ to account for the non-linear response of sleepers; they reported measurements made on a 20-sleeper length of railway track in Sweden using an instrumented, stationary wagon able to apply cyclic loading. These measurements showed that the stiffness at $2 \mathrm{~Hz}$ varied by a factor of at least 2 between sleepers, and increased with the applied load.

Nguyen et al. ${ }^{[29]}$ described an approach to track geometry prediction based on a finite element representation of the track with input geometry from real track. A track settlement relationship was implemented relating plastic strain to stress, and the analysis was run to predict settlement along a case study section of track. A variable stiffness was not a direct input to the model, hence the variation in loading along the track arose as a result of the initial geometry and the settlement as it evolved. The model captured some key elements of track behaviour; for example, that initial local defects tended to become amplified with increasing number of cycles. The results showed reasonable agreement with the measured settlement at the case study site. However, the study applied only 50,000 cycles and is not yet generalizable or validated for longer term prediction. More recently, Nielsen \& $\mathrm{Li}^{[30]}$ described an iterative train/track interaction model to predict long-term degradation of longitudinal level due to accumulated differential settlement using a version of Sato's ${ }^{[27]}$ relationship.

Grossoni et al., ${ }^{[31]}$ developed a stochastic model to predict track stiffness using an autoregressive integrated moving average (ARIMA) method calibrated against falling weight deflectometer (FWD) estimates of trackbed stiffness from two sites comprising 155 and 80 sleepers. The ARIMA method allowed for dependence between sleepers and weighted a number of preceding sleepers for their influence on the stiffness of the current sleeper. This work identified that the coefficients applied in the ARIMA formulation were necessarily different for the two sites - i.e. that no single overarching stochastic model suitable for both sites could be found. Differences in underlying geology as well as in the components of the track form could explain this finding. Normal distributions were fitted to the measured data. However, the measured (FWD) data correspond to the support stiffness for unclipped sleepers representing a best (highest) value. The unclipping also arguably removes an element of interdependence in the reponse as seen by passing trains. The models were used in parametric studies to evaluate the evolution of track settlement, to show that spatial variability of stiffness had a significant influence on the development of track irregularities.

The few studies that have attempted to quantify stochastically the variability of the track support have tended to rely on relatively few data points and different methods of track stiffness measurement, none of which explicitly capture the track support stiffness as seen by in-service trains.

\section{Methods and measurements}

For the current study, field measurements were carried out over 209 continuous sleepers. The objective of these measurements was to obtain a dataset of time-movement records for successive sleepers for multiple passages of a single train type. These data were then analysed in the frequency 
domain to estimate the support system and trackbed modulus at each measurement location. In this paper, the following definitions of track stiffness are used ${ }^{[7]}$ :

- the support system modulus $\left(\boldsymbol{k}_{\text {sys }}\right)$ is the load per unit length causing a unit displacement at the rail

- the railpad modulus $\left(\boldsymbol{k}_{\text {pad }}\right)$, the load per unit length causing a unit displacement of the railpad, and

- the trackbed modulus ( $\left.\boldsymbol{k}_{\text {trackbed }}\right)$, the load per unit length causing a unit displacement of the sleeper.

The three are related through the equation $\left(1 / \mathrm{k}_{\text {sys }}=1 / \mathrm{k}_{\text {pad }}+1 / \mathrm{k}_{\text {tracked }}\right)$. Where the properties of the railpad are known, measurements of the support system modulus can be used to infer the trackbed modulus.

\section{Methods}

\section{Instrumentation}

Micro-Electro-Mechanical systems (MEMs) accelerometers were used. These were based on the ADXL345 accelerometer from Analog Devices, and selected following a laboratory evaluation ${ }^{[32]}$. Each accelerometer was supplied as a standalone, battery-powered data logging system, costing around $£ 100$, convenient for short term deployment.

The sensors were configured to operate with a $\pm 16 \mathrm{~g}$ range and slotted into brackets glued onto sleeper/bearer surfaces (Figure 1). Data were recorded continuously at $400 \mathrm{~Hz}$ during deployment, with eight times oversampling to achieve 16-bit resolution.

80 MEMs accelerometers were used; these were moved along the track during 3 consecutive night time possessions in January 2018, with the data downloaded at the end of the monitoring period. Individual train passages were identified and $20 \mathrm{~s}$ of associated data extracted for each one. Data were processed in MATLAB and converted to frequency spectra and time/deflection traces following established procedures (see e.g. ${ }^{[33]}$ ).

\section{Processing}

The acceleration records for individual sleeper movements can be interpreted using the beam on an elastic foundation (BOEF) model ${ }^{[34]}$ for a typical train, in this case a 6 car Class 395 Javelin electric multiple unit (emu).

Figure 2 shows a theoretical deflection trace for two different values of support system modulus. The $x$-axis units have been converted to vehicle passes. Each vehicle is $20 \mathrm{~m}$ long with axles located at $1.6,3.8,15.8$ and $18.4 \mathrm{~m}$ from the vehicle start. The wheel load was taken as $53.5 \mathrm{kN}$, which is the published static wheel load for this type of train.

The acceleration, velocity or deflection traces can be converted to frequency spectra by applying a Fast Fourier Transform (FFT). This is done for the acceleration spectrum of the Class 395 in Figure 3, for three different values of system support modulus for a train travelling at $20 \mathrm{~m} / \mathrm{s}$ so that $1 \mathrm{~Hz}$ corresponds to the vehicle passing frequency. Dashed lines highlight the influence of the support system modulus in the relative magnitudes of the $3^{\text {rd }}$ and $7^{\text {th }}$ multiples of the vehicle passing frequencies.

The change in the relative magnitudes of selected frequency peaks can be used to develop a calibration curve to infer the support system modulus from field measurements ${ }^{[35,36]}$. Figure 4 
shows the relationship between the ratio of the $7^{\text {th }}$ to $3^{\text {rd }}$ harmonics of the vehicle passing frequency and the system support modulus for acceleration, velocity and displacement spectra.

\section{Site details}

The site was an extension to one used in a previous study ${ }^{[37]}$, and was selected as representative of a normally/well operating section of plain line high speed straight track (Figure 5).

The track comprised CEN 60 E1 rails on Vossloh ZW900 railpads supported by twin block sleepers at $0.6 \mathrm{~m}$ spacing. The railpads were tested in the laboratory ${ }^{[38]}$ and found to have an effective spring stiffness of $84 \mathrm{kN} / \mathrm{m}$ over load increment corresponding approximately to a train axle load. This was converted to a track modulus for the railpad by dividing by the sleeper spacing.

There is a gravel area for car access adjacent to the first part of the site with a cutting slope on the other side (Figure 5). As the line continues (passing the observation point of Figure 5 in the direction of train movement) the cutting slope on the car park side closes in. Prior to the construction of the route, local boreholes showed that the underlying ground comprised a $<1.0 \mathrm{~m}$ thick layer of firm sandy CLAY or clayey SAND overlying dense to very dense SAND. The trackbed is therefore likely built onto the dense to very dense SAND.

\section{Measurements}

Characteristic results are presented for the passage of a 6 car class 395. Generally, 12 passages of these trains were recorded at each transducer location. Evaluation of these measurements indicated that most trains were travelling at approximately $60 \mathrm{~m} / \mathrm{s}$. The data were consistent between each train; the average deflections are shown in Figure 6.

Figure 6 (a) shows a general minimum sleeper deflection of approximately $0.4 \mathrm{~mm}$. There are localised faults where the deflection increases over a distance of a few sleepers, reaches a peak and then gradually reduces back to a lower, more consistent deflection. This can be seen (for example) between sleepers 10 and 20 . There are occasionally double features, for example between sleepers 95 and 115 . Figure 6 (b) shows the variation in support system modulus inferred directly from the frequency spectra and the corresponding trackbed modulus, calculated by removing the compliance of the railpad. The results are presented as a histogram in Figure 7. These data are not normally distributed; the spread is positive skewed.

\section{Evaluation of track stiffness data for dependencies between sleepers}

Figure 7 shows the overall distribution of trackbed moduli at the site. However, the nature of the track system suggests that the track stiffness at an individual sleeper would be expected to be related to those close to it, and principally to the sleeper immediately preceding it in the direction of train travel. The hypothesis that the spatial distribution of trackbed support is not random but depends on the value at the preceding sleeper can be tested using mathematical reasoning.

Using the BOEF model (e.g. ${ }^{[2,34,39]}$ ) it can be shown that, for a range of plausible uniform track support system moduli, approximately $40 \%$ to $70 \%$ of the load from an axle directly above a sleeper is transferred to the sleeper immediately below, with most of the remaining load passing evenly to the sleepers immediately on either side. Components of load transferred further along the track are generally relatively small (e.g. ${ }^{[3]}$ ). This implies that the support stiffness of adjacent sleepers is related through a feedback loop that may be described thus: because three adjacent sleepers must together simultaneously support a passing axle, if one sleeper has or develops a softer support 
compared with those around it, the more softly supported sleeper passes a greater proportion of load onto adjacent sleepers. The adjacent sleepers are then overloaded so that they develop permanent settlement at a faster rate, further softening the support.

Field data show that it is rare for trackside measurements of sleeper movements to go from one extreme (low deflection) to the other (high deflection) on adjacent sleepers. Where trackbed faults are present, a softer support usually develops gradually, with a region of poor support changing gradually to a more usual support condition on both sides. This is seen in the data in Figure 6(a).The dependency between adjacent sleepers can be demonstrated probabilistically using the autocorrelate (ACF) and partial auto-correlate (PACF) functions. The ACF can be applied to quantify the correlation coefficient for the trackbed modulus between sleepers at different multiples of sleeper spacing away. The PACF gives the correlations with the linear dependences from any intermediate sleepers removed.

The ACF is commonly estimated using the ratio of the sample auto covariance and variance:

$$
r_{\tau}=\frac{\frac{1}{N} \sum_{x=1}^{N-\tau}\left(k_{x+\tau}-\bar{\mu}\right)\left(k_{x}-\bar{\mu}\right)}{s^{2}}
$$

Equation 1

where $r_{\tau}$ is the correlation coefficient, which in the current context applies for a sleeper spacing $\tau$, modulus $k$ (at the position specified by the subscript), mean modulus $\bar{\mu}$ and variance of the modulus $s^{2}$. This may be applied to either support system support modulus or to the trackbed modulus.

Figure 8 shows the ACF and PACF for the trackbed modulus profile shown in Figure 6(b).

Figure 8 shows that there is a correlation between adjacent sleepers, which reduces substantially for sleepers more than 1 space further away (lags of 2 and above). A correlation coefficient of zero may be expected for large data sets with no correlation, however for smaller data sets, low values of apparent correlation may occur that are not indicative of any meaningful correlation. The PACF shows that the correlation is significant for the adjacent sleeper and confirms that the data are first order autoregressive ${ }^{[40]}$, i.e. that any correlation between sleepers more than one apart is due to correlation between the intermediate sleepers.

To further demonstrate the spatial dependence, the data can be banded by trackbed modulus range and the statistics within each band examined in more detail. A suitable trackbed modulus banding is obtained by taking the 52 sleepers with the highest modulus, the 52 with the lowest and two intermediate bands (Table 1). The overall mean for the data set is $35.4 \mathrm{MN} / \mathrm{m}^{2}$, which lies in band 3 .

These bands can be interrogated statistically to assess the interdependence between the trackbed moduli of adjoining sleepers. Statistics for the current sleeper trackbed modulus based on the band in which that of the preceding sleeper lies are presented in Table 2 and Figure 9.

Figure 9 further demonstrates that the stiffness of a sleeper is related to those immediately adjacent to it; if this were not the case, the distribution lines for all bands would have been the same.

\section{Developing a stochastic framework using the measured data}

A framework is proposed for the stochastic description of track stiffness, using the field measurements to calibrate suitable distribution functions. 
The dependence between the trackbed modulus of adjacent sleepers indicates the suitability of a Markov prediction model which is applicable when the future state of a process depends only on the current state, but not on its past states ${ }^{[41]}$. I.e., the track support modulus at the next sleeper $(x+1)$ can be predicted with knowledge of only the track support modulus at the preceding or current sleeper $(\mathrm{x})$ and a probability distribution relating the two. Markov models have been used in a variety of applications including predicting deterioration of road pavements (e.g. ${ }^{[42]}$ ). Strictly, a Markov model is applicable where there is a countable state space; here, the state space is potentially continuous between upper and lower limits. However for practical purposes, the trackbed modulus can reasonably be restricted to performance bands.

The proposed application of a Markov model is illustrated schematically in Figure 10. This relies on the use of the measured data for the development of a transition array of probabilities to permit the current track modulus to be used to infer the likely distribution of probability for the support modulus of the next sleeper.

To apply step 2 of Figure 10, distributions can be generated from the field data by fitting candidate functions to the four bands of data shown in Figure 9.

\section{Selection of distribution functions}

The overall data set (Figure 7) is skewed and does not follow a normal distribution. Furthermore, between bands the distributions vary. In this section Weibull and Gamma distributions are evaluated. These were selected because they are able to reproduce the observed skew in the overall data set, but may also have their shapes and scales adjusted to produce symmetric distributions if required.

\section{Weibull distribution and probability density functions}

Weibull functions have previously been applied successfully to other geotechnical engineering problems (e.g. ${ }^{[43 \& 44]}$ ).

The Weibull cumulative distribution function (CDF) is given by:

$$
C D F=1-e^{-\left(\frac{x}{a}\right)^{b}} \quad \text { Equation } 2
$$

The Weibull probability density function (PDF) is given by:

$$
P D F=b a^{-b} x^{b-1} e^{-\left(\frac{x}{a}\right)^{b}}
$$

Equation 3

Where $\boldsymbol{a}$ is the scale parameter and $\boldsymbol{b}$ is the shape parameter ${ }^{[45]}$. The mean and variance are not directly available from the shape and scale parameters although they can be found numerically as:

$$
\mu=\lambda \Gamma\left(1+\frac{1}{a}\right)
$$




$$
\sigma^{2}=a^{2}\left(\Gamma\left(1+\frac{2}{b}\right)-\left(\Gamma\left(1+\frac{1}{b}\right)\right)^{2}\right)
$$

where $\Gamma$ is the gamma function (not to be confused with Gamma probability functions so named because they explicitly include the gamma functions within the PDF and CDF).

\section{Gamma distribution and probability density functions}

The Gamma probability functions are defined by:

$$
\begin{gathered}
C D F: \frac{1}{\Gamma(k)} \gamma\left(k, \frac{x}{\theta}\right) \\
P D F: \frac{1}{\Gamma(k) \theta^{k}} x^{k-1} e^{-\frac{x}{\theta}}
\end{gathered}
$$

Equation 6

Equation 7

where $\Gamma$ is the Gamma function, $\gamma$ is the lower incomplete gamma function, $k$ is the shape function and $\boldsymbol{\theta}$ is the scale parameter,

$\boldsymbol{k}$ and $\theta$ are related to the mean $(\mu)$ and variance $\left(\sigma^{2}\right)$ of the distribution by:

$$
\begin{array}{ll}
\mu=k \theta & \text { Equation } 8
\end{array}
$$

and

$$
\sigma^{2}=k \theta^{2}
$$

Equation 9

\section{Comparison of candidate distributions}

The Weibull and Gamma cumulative distributions can be fitted to the distribution curves shown in Figure 9 using a maximum likelihood approach. This gives the parameter values in Table 3.

Figure $11(a \& b)$ shows the fitted cumulative distribution functions and the four bands of measured data for (a) the Weibulll distribution and (b) the Gamma distribution. Figure 11 (c \& d) shows the corresponding probability distribution functions.

Figure $11(c \& d)$ shows that both distribution types reflect key characteristics of the site data. Band 1 is the lowest stiffness band. If the sleeper trackbed modulus falls within this band, the PDF is skewed to the lower end, increasing the likelihood that the next sleeper falls within the same band. Band 2 is also skewed towards its lower end. Bands 3 and 4 are more symmetrical peaking at or close to the overall mean for the data set $\left(35.4 \mathrm{MN} / \mathrm{m}^{2}\right)$. This suggests that when the trackbed modulus is high, the trackbed modulus of the next sleeper is likely to be pushed back towards the overall mean for the data set. Conversely, when the trackbed modulus is low, the modulus of the next sleeper is more likely to be below the overall mean.

Figure 12 shows Weibull and Gamma distributions fitted to the full data set, these confirm the overall range of likely outcomes. The Weibull and Gamma fitted distributions indicate that the maximum trackbed modulus likely to be encountered in practice in 1 in 10,000 occasions is $148 \mathrm{MPa}$ and $183 \mathrm{MPa}$ respectively. 


\section{Extension to continuous probability}

The Markov chain developed from banding implicitly accounts for the dependencies between adjacent sleepers. However, application of the framework (Figure 10) over relatively few bands is sensitive to band boundaries. It may therefore be advantageous to eliminate this sensitivity by using continuous conditional probabilities. Figure 13 shows the mean and standard deviation for the current sleeper $(x)$ plotted against the equivalent parameters from the four bands of measured data for the next sleeper $(x+1)$. The coefficient of variability, which provides a measure of the relative dispersion of the distribution, is also plotted on the secondary axis.

Figure 13 shows an approximately linear relationship between the mean trackbed modulus of adjacent sleepers $(x$ and $x+1)$. The gradient of the line is approximately the correlation coefficient from the auto-correlate or partial auto-correlate functions. However, applying the least squares fit to the mean of each bands has led to a small discrepancy - the gradient of the line in Figure 13 is 0.46 , while the correlation coefficient was 0.42 .

Figure 13 shows that the sample standard deviation increases as the trackbed modulus of a sleeper moves away from the approximate centre (between bands 2 and 3 ) of the data set (a mean of 35.4 $\mathrm{MPa}$ ), where it is a minimum. The exact position of the minimum is subject to uncertainty owing to the relatively small number of data bands. A quadratic function fitted to the data captures this. While it is possible to use the fitted function between the extreme bands ( 1 and 4 ), no more information is available outside the upper and lower bands because these bands define the limits for the full data set (Figure 12). Gathering more data could allow the data to be reliably divided into greater numbers of bands. The coefficient of variability shows that in relative terms the standard deviation in lower bands is more significant compared to the mean for that band than in higher bands, but reduces to a constant value as the stiffness exceeds approximately the mean for the whole population (35.4 MPa).

A minimum in the standard deviation and a reduction towards a constant coefficient of variability suggest there may be a typical/optimal value of track stiffness and inherent level of variability for a given track form, level of maintenance, and underlying geology; this seems intuitively reasonable. When the trackbed modulus is significantly higher or lower than the mean, the track properties in the vicinity become more variable. This can be interpreted as implying that trackbed faults potentially indicative of poor or overly stiff support are likely to extend over a number of sleepers (Figure 6).

The ACF and PACF suggested that a first order autoregressive model (a Markov process) would be appropriate for determining conditional probabilities. However, in a first order autoregressive model it is generally assumed that data are normally distributed with zero mean and constant independent standard deviation. This is not suitable for modelling track stiffness, which is always positive and may have a stiffness-dependent standard deviation as well as upper and lower limits. Nonetheless, the autoregressive terms can be used to describe how the mean expected trackbed modulus at a sleeper depends on that of the previous sleeper:

$$
\mu_{x+1}=\bar{\mu}+C\left(k_{x}-\bar{\mu}\right)
$$

Equation 10

where $\overline{\boldsymbol{\mu}}$ is the overall mean, $\boldsymbol{C}$ is the correlation coefficient of the ACF or the gradient in Figure $13, \mathrm{k}_{\mathrm{x}}$ is the support stiffness at the preceding/current sleeper, $\mu_{x+1}$ is the mean for the distribution of the next sleeper. The terms that vary in Equation 10 are the support stiffness at the current sleeper $(x)$ and the mean of the distribution for the next sleeper $(x+1)$. The mean of the distribution for the current sleeper may be used to determine the probability CDF for the next sleeper using inferred 
relationships for the shape and scale coefficients for the selected distribution function (e.g. as implied by Figure 13).

A partial implementation of Equation 10 omitting the stochastic elements is shown in Figure 14, in which the measured trackbed modulus for the current sleeper $(x)$ has been used to forecast the standard deviation and mean value of the following sleeper $(x+1)$.

Figure 14 shows that in most cases the trackbed modulus for the next sleeper falls within $+/$ - one standard deviation, and that the mean forecast follows a similar pattern to the measured data. The most severe trackbed faults are present where the measured data falls outside the predicted deviation range.

The stochastic (random) terms of Equation 10 may be implemented following the process set out in Figure 10 using the quadratic fit to the standard deviation shown in Figure 13 and applying the Weibull and Gamma CDFs from the mean and variance (Equations 2 to 9). However, the application of a stiffness-dependent standard deviation is a departure from the techniques normally applied for first order autoregressive modelling. Also, the trackbed moduli generated using a stiffnessdependent standard deviation and limits on the upper and lower distributions will not reproduce the same autocorrelation coefficients produced by the measured data (requiring the standard deviation to remain constant, not providing limits and a linearly-varying mean would necessarily lead to this outcome). Given these observations, it was considered appropriate to use in Equation 10 the correlation coefficient $\mathrm{C}$ obtained from the linear fit in Figure 13 of 0.46 , rather than the lower value of 0.42 determined from the ACF.

Simulations of the variation in trackbed modulus for 10,000 sleepers were carried out using the same sequence of randomly generated numbers between 0 and 1 for the banded and continuous Gamma and Weibull distributions presented. Extracts of 100 sleepers from these simulations are shown in Figure 15; sample statistics for all 10,000 sleepers and a subset of the first 209 in the same simulation are illustrated as boxplots in Figure 16; summary statistics are given in Table 4.

Greater differences for the predicted trackbed modulus between the banded and continuous implementations occur when the distribution for the next sleeper moves to a different band in the banded implementation. However, the sensitivity to band boundaries is generally small as a proportion of the values predicted.

Repeat simulations for fewer data points (e.g. 209) such as those shown in Figure 16(a) have an inherent variability of outcome, and repeat simulations could lead to data sets with a greater or lesser degree of match with the measured data. As the number of sleepers in the simulation is increased, so does the repeatability in a statistical sense. For 10,000 sleepers the repeatability is very good, but repeat simulations can still lead to the maximum and minimum outliers changing noticeably.

For the full data set, the autocorrelation coefficient in the Weibull continuous and banded simulations stabilises at 0.37 and 0.38 respectively (Table 4). For the Gamma distribution, the corresponding values are 0.36 and 0.35 . Over any selection of 209 sleepers from the simulations, the correlation coefficient varies and in some cases matches that for the 209 measured trackbed moduli (0.42).

\section{Conclusions}

Data have been presented from field measurements of deflection and track support system stiffness for a continuous run of 209 sleepers on a highly engineered, well-maintained high speed railway. 
The data indicate a level of variability, statistical analysis of which has demonstrated a number of interesting and important characteristics.

1. Banding the measured data and evaluation using the ACF has shown the statistical dependence of the trackbed modulus at an individual sleeper on the moduli of the sleepers immediately adjacent to it. Analysis using the partial auto-correlate function (PACF) has demonstrated that, in terms of their influence on stiffness, consideration of sleepers further away is unnecessary.

2. There is an optimum trackbed stiffness, close to the overall mean value, at which the standard deviation is a minimum. As the trackbed stiffness moves away from the optimum value, the likely variability in trackbed stiffness from sleeper to sleeper increases.

3. The standard deviation of the trackbed modulus becomes more significant (as a proportion of the local mean) for bands below the mean.

A framework for implementing a stochastic approach to predicting the variation in track support stiffness from one sleeper to another, based on a Markov model and selected probability functions, has been proposed. Within this framework, a modified first order autoregressive model using a positive valued two parameter distribution (e.g. Weibull or Gamma), a stiffness dependent standard deviation and limits on the upper and lower distributions is able to reproduce key features of measured trackbed modulus, particularly its variation from sleeper to sleeper.

The framework and implementation developed may be used for quantitative comparison of different sites, and provides a method for simulating plausible values of track stiffness and variation therein in vehicle-track interaction analysis.

\section{Acknowledgements}

The authors are grateful for the financial support of the Engineering and Physical Sciences Research Council (EPSRC) through the Programme grant Track to the Future (EP/M025276/1)), support from HS1 and in particular the assistance of Mick Hayward and other HS1 employees. All data supporting this study are openly available from the University of Southampton repository at XXX.

\section{References}

1. Abadi T, Le Pen L, Zervos A, Powrie W. Measuring the area and number of ballast particle contacts at sleeper/ballast and ballast/subgrade interfaces. The International Journal of Railway Technology. 2015;4(2):45 to 72.

2. Raymond GP. Analysis of Track Support and Determination of Track Modulus. Transportation Research Record. 1985;1022:80-90.

3. Le Pen L, Watson G, Hudson A, Powrie W. Behaviour of under sleeper pads at switches and crossings - Field measurements. Proceedings of the Institution of Mechanical Engineers, Part F: Journal of Rail and Rapid Transit. 2018;232(4):1049-63.

4. Union International des Chemins de Fer. UIC 719R, Earthworks and track bed for railway lines, 3rd edition, February 2008.

5. Network Rail NR/SP/TRK/9039 Business Process Document: Formation Treatments, Issue 1, Dec 2005, Network Rail, 40 Melton Street, London, W1 2EE, 2005.

6. Bowness D, Lock AC, Powrie W, Priest JA, Richards DJ. Monitoring the dynamic displacements of railway track. Proceedings of the Institution of Mechanical Engineers, Part F: Journal of Rail and Rapid Transit. 2007;221(F1):13-22. 
7. TSWG. A Guide to Track Stiffness, Edited by W. Powrie, \& L Le Pen on behalf of the cross industry track stiffness working group (TSWG). Southampton. Southampton, UK: University of Southampton, UK, ISBN: 9780854329946.; 2016. Available from:

https://www.thepwi.org/technical_hub/technical_hub_files/a_guide_to_track_stiffness_final_revie wr11.

8. Sussman T, Ebersöhn W, Selig E. Fundamental Nonlinear Track Load-Deflection Behavior for Condition Evaluation. Transportation Research Record: Journal of the Transportation Research Board. 2001;1742:61-7.

9. Oscarsson J. Simulation of train-track interaction with stochastic track properties. Vehicle System Dynamics. 2002;37(6):449-69.

10. Oscarsson J. Dynamic train-track-ballast interaction with unevenly distributed track properties. Vehicle System Dynamics. 2003;37(SUPPL):385-96.

11. Hunt GA. Review of the Effect of Track Stiffness on Track Performance for the Rail Safety and Standards Board (RSSB), Research project T372. AEA Technology Rail, Jubilee House, 2005.

12. Li D, Davis D. Transition of Railroad Bridge Approaches. Journal of Geotechnical and Geoenvironmental Engineering. 2005;131(11):1392-8.

13. Dong, K., Connolly, D. P., Laghrouche, O., Woodward, P. K. \& Alves Costa, P. (2018) The stiffening of soft soils on railway lines. Transportation Geotechnics, Vol.17, pp.178-191.

14. Coelho B, Hölscher P, Priest J, Powrie W, Barends F. An assessment of transition zone performance. Proceedings of the IMechE Part F, Journal of Rail and Rapid Transit. 2011;225(129):129.

15. Banimahd M, Woodward PK, Kennedy J, Medero GM. Behaviour of train-track interaction in stiffness transitions. Proceedings of the ICE - Transport [Internet]. 2012; 165:[205-14 pp.]. Available from: http://www.icevirtuallibrary.com/content/article/10.1680/tran.10.00030.

16. Insa R, Salvador P, Inarejos J, Roda A. Analysis of the influence of under sleeper pads on the railway vehicle/track dynamic interaction in transition zones. Proceedings of the Institution of Mechanical Engineers, Part F: Journal of Rail and Rapid Transit. 2012; 226(4):409-20.

17. Tutumluer E, Stark TD, Mishra D, Hyslip JP. Investigation and Mitigation pf Differential Movement at Railway Transitions for US High Speed Passenger Rail and Joint Passenger/Freight Corridors. Proceedings of the 2012 Joint Rail Conference, JRC2012; April 17-19, 2012, Philadelphia, Pennsylvania, USA.

18. Paixao A, Fortunato E, Calcada R. Design and construction of backfills for railway track transition zones. Proceedings of the Institution of Mechanical Engineers, Part F: Journal of Rail and Rapid Transit. 2013 August 28, 2013.

19. Mishra D, Qian Y, Huang H, Tutumluer E. An integrated approach to dynamic analysis of railroad track transitions behavior. Transportation Geotechnics. $2014 ; 1(4): 188-200$.

20. Muramoto K, Nakamura T, Sakurai T, editors. A track irregularity prevention method for the transition zone between different track structures using Automatic Irregularity-correcting Sleeper. World Congress on Railway Research; 2013; Sydney, Australia.

21. Varandas JN, Hölscher P, Silva MA. Settlement of ballasted track under traffic loading: Application to transition zones. Proceedings of the Institution of Mechanical Engineers, Part F: Journal of Rail and Rapid Transit, 2014;228(3):242-59.

22. Hunt GA. EUROBALT optimises ballasted track. Railway Gazette International. 2000;156(12):813.

23. Abadi T, Pen LL, Zervos A, Powrie W. Improving the performance of railway tracks through ballast interventions. Proceedings of the Institution of Mechanical Engineers, Part F: Journal of Rail and Rapid Transit. 2018; 232(2):337-55.

24. Abadi T, Le Pen L, Zervos A, Powrie W. A Review and Evaluation of Ballast Settlement Models using Results from the Southampton Railway Testing Facility (SRTF). Procedia Engineering. 2016 143:999-1006. 
25. Dahlberg T. Some railroad settlement models-A critical review. Proceedings of the Institution of Mechanical Engineers, Part F: Journal of Rail and Rapid Transit. 2001;215(4):289-300.

26. Guerin N. Approche experimentale et numerique du comportement du ballast des voies ferrees: Ecole Nationale des Ponts et Chausees; 1996.

27. Sato Y. Japanese Studies on Deterioration of Ballasted Track. Vehicle System Dynamics. 1995 1995/01/01;24(sup1):197-208.

28. Nielsen JCO, Oscarsson J. Simulation of dynamic train-track interaction with state-dependent track properties. Journal of Sound and Vibration. 2004;275(3-5):515-32.

29. Nguyen K, Villalmanzo DI, Goicolea JM, Gabaldon F. A computational procedure for prediction of ballasted track profile degradation under railway traffic loading. Proceedings of the Institution of Mechanical Engineers, Part F: Journal of Rail and Rapid Transit. 2015.

30. Nielsen JCO, Li X. Railway track geometry degradation due to differential settlement of ballast/subgrade - Numerical prediction by an iterative procedure. Journal of Sound and Vibration. 2018 2018/01/06/;412:441-56.

31. Grossoni I, Andrade A, Bezin Y, Neves S. The role of track stiffness and its spatial variability on long-term track quality deterioration. Proceedings of the Institution of Mechanical Engineers, Part F: Journal of Rail and Rapid Transit. Online ahead of print 2018, https://doi.org/10.1177/0954409718777372

32. Milne D, Le Pen L, Watson G, Thompson D, Powrie W, Hayward M, et al. Proving MEMS Technologies for Smarter Railway Infrastructure. Procedia Engineering. 2016 //;143:1077-84.

33. Shin K, Hammond J. Fundamentals of Signal Processing for Sound and Vibration Engineers. John Wiley and Sons Ltd, The Atrium, Southern Gate, Chichester, West Sussex, PO19 8SQ, England, 2008.

34. Timoshenko S, editor Methods of Analysis of Statical and Dynamical Stresses in Rails. The Second International Congress of Applied Mechanics; 1927; Zurich, Switzerland.

35 Le Pen L, Milne D, Thompson D, Powrie W. Evaluating railway track support stiffness from trackside measurements in the absence of wheel load data. Canadian Geotechnical Journal. 2016/07/01;53(7):1156-66.

36. Milne DRM, Le Pen LM, Thompson DJ, Powrie W. Properties of train load frequencies and their applications. Journal of Sound and Vibration. 2017/06/09/;397(Supplement C):123-40.

37. Soper D, Baker C, Jackson A, Milne DR, Le Pen L, Watson G, et al. Full scale measurements of train underbody flows and track forces. Journal of Wind Engineering and Industrial Aerodynamics. 2017/10/01/;169:251-64.

38. Institution BS. BS EN 13146-9:2009+A1:2011 Railway applications. Track. Test methods for fastening systems. Determination of stiffness. British Standards Institution, London, UK2010.

39. Esveld C. Modern Railway Track. 2nd ed. ed. Zaltbommel: MRT Productions; 2001. xxvi, 653

p. p.

40. Box G.E.P, Jenkins G.M., Reinsel G.C., G.M. L. Time Series Analysis: Forecasting and Control, 5th Edition: Wiley; 2015. 712 p.

41. Isaacson DL, Madsen RW. Markov chains, theory and applications New York: Wiley; 1976.

42. Ortiz-García JJ, Costello SB, Snaith MS. Derivation of Transition Probability Matrices for Pavement Deterioration Modeling. Journal of Transportation Engineering. 2006;132(2):141-61.

43. McDowell GR. Statistics of soil particle strength. Geotechnique. 2001;51(10):90.

44. Le Pen L, Powrie W, Zervos A, Ahmed S, Aingaran S. Dependence of shape on particle size for a crushed rock railway ballast. Granular Matter, Springer Berlin Heidelberg. 2013.

45. Weibull W. A Statistical Distribution Function of Wide Applicability. Journal of Applied Mechanics. 1951;18:293-7. 


\section{$\underline{\text { Tables }}$}

\begin{tabular}{|l|l|l|l|}
\hline Band & $\begin{array}{l}\text { Lower bound } \\
\left(\mathrm{MN} / \mathrm{m}^{2}\right)\end{array}$ & $\begin{array}{l}\text { Upper Bound } \\
\left(\mathrm{MN} / \mathrm{m}^{2}\right)\end{array}$ & $\begin{array}{l}\text { Mean value } \\
\left(\mathrm{MN} / \mathrm{m}^{2}\right)\end{array}$ \\
\hline 1 & 2.4 & 21.8 & 12.4 \\
\hline 2 & 21.8 & 31.7 & 26.1 \\
\hline 3 & 31.7 & 46.5 & 39.1 \\
\hline 4 & 46.5 & 147.5 & 64.7 \\
\hline
\end{tabular}

Table 1: Preceding sleeper trackbed modulus bands selected for approximately equal populations (52) in each band

\begin{tabular}{|l|l|l|l|}
\hline Band & $\begin{array}{l}\text { Lower bound } \\
\left(\mathrm{MN} / \mathrm{m}^{2}\right)\end{array}$ & $\begin{array}{l}\text { Upper Bound } \\
\left(\mathrm{MN} / \mathrm{m}^{2}\right)\end{array}$ & $\begin{array}{l}\text { Mean value } \\
\left(\mathrm{MN} / \mathrm{m}^{2}\right)\end{array}$ \\
\hline 1 & 2.4 & 78.3 & 26.2 \\
\hline 2 & 4.4 & 122.8 & 27.4 \\
\hline 3 & 5.1 & 87.7 & 39.5 \\
\hline 4 & 3.6 & 147.5 & 48.4 \\
\hline
\end{tabular}

Table 2: Current sleeper trackbed modulus for band of preceding sleeper

\begin{tabular}{|c|c|c|c|c|}
\hline \multirow{3}{*}{ Band } & \multicolumn{4}{|l|}{ Distribution } \\
\hline & \multicolumn{2}{|l|}{ Weibull } & \multicolumn{2}{|l|}{ Gamma } \\
\hline & $\mathrm{a}$ & $b$ & $\boldsymbol{k}$ & $\boldsymbol{\theta}$ \\
\hline 1 & 29.100 & 1.484 & 1.977 & 13.265 \\
\hline 2 & 30.796 & 1.706 & 3.212 & 8.514 \\
\hline 3 & 44.356 & 2.549 & 4.589 & 8.614 \\
\hline 4 & 54.494 & 1.933 & 3.004 & 16.122 \\
\hline Overall data set & 39.80 & 1.69 & 2.49 & 14.26 \\
\hline
\end{tabular}

Table 3: Gamma and Weibull distribution parameters

\begin{tabular}{|l|l|l|l|l|l|}
\hline & \multicolumn{4}{|l|}{ Trackbed modulus (MPa) } & \\
\hline Data (number of sleepers) & Mean & SD & Max & Min & $\begin{array}{l}\text { Autocorrelation } \\
\text { coefficient }\end{array}$ \\
\hline $\begin{array}{l}\text { Simulated Weibull Continuous, } \\
(10,000)\end{array}$ & 34.81 & 20.43 & 144.8 & 0.059 & 0.37 \\
\hline Simulated Weibull Banded, (10,000) & 34.56 & 20.13 & 162.2 & 0.338 & 0.38 \\
\hline $\begin{array}{l}\text { Simulated Gamma Continuous, } \\
(10,000)\end{array}$ & 34.53 & 21.61 & 145.3 & 0.0448 & 0.36 \\
\hline Simulated Gamma Banded, (10,000) & 34.90 & 21.98 & 176.2 & 0.145 & 0.35 \\
\hline Measured (209) & 35.5 & 21.9 & 148 & 2.4 & 0.42 \\
\hline
\end{tabular}

Table 4: Summary statistics for simulations and measured data

\section{Figure Captions}




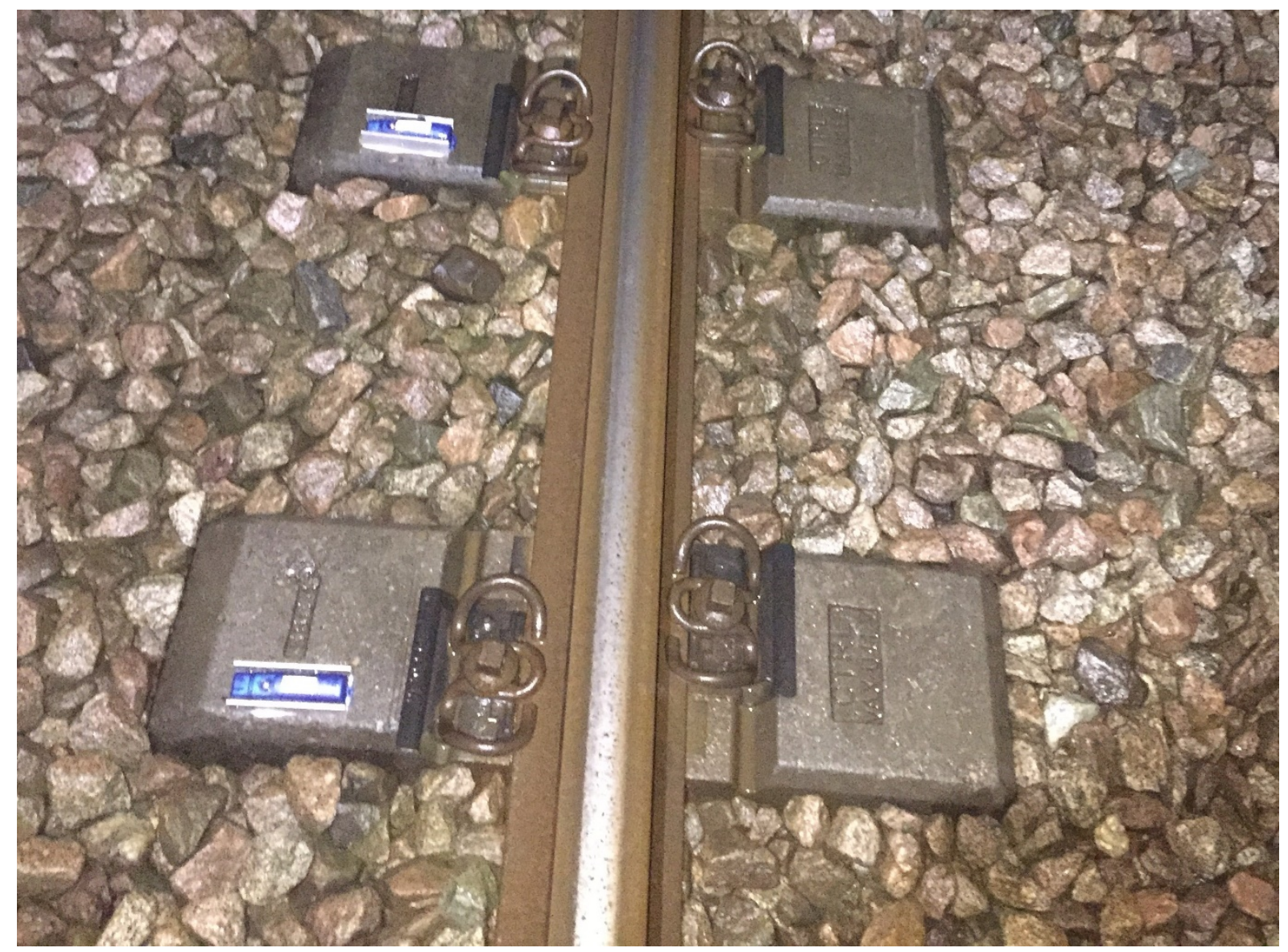

Figure 1: MEMs accelerometers mounted on sleeper ends

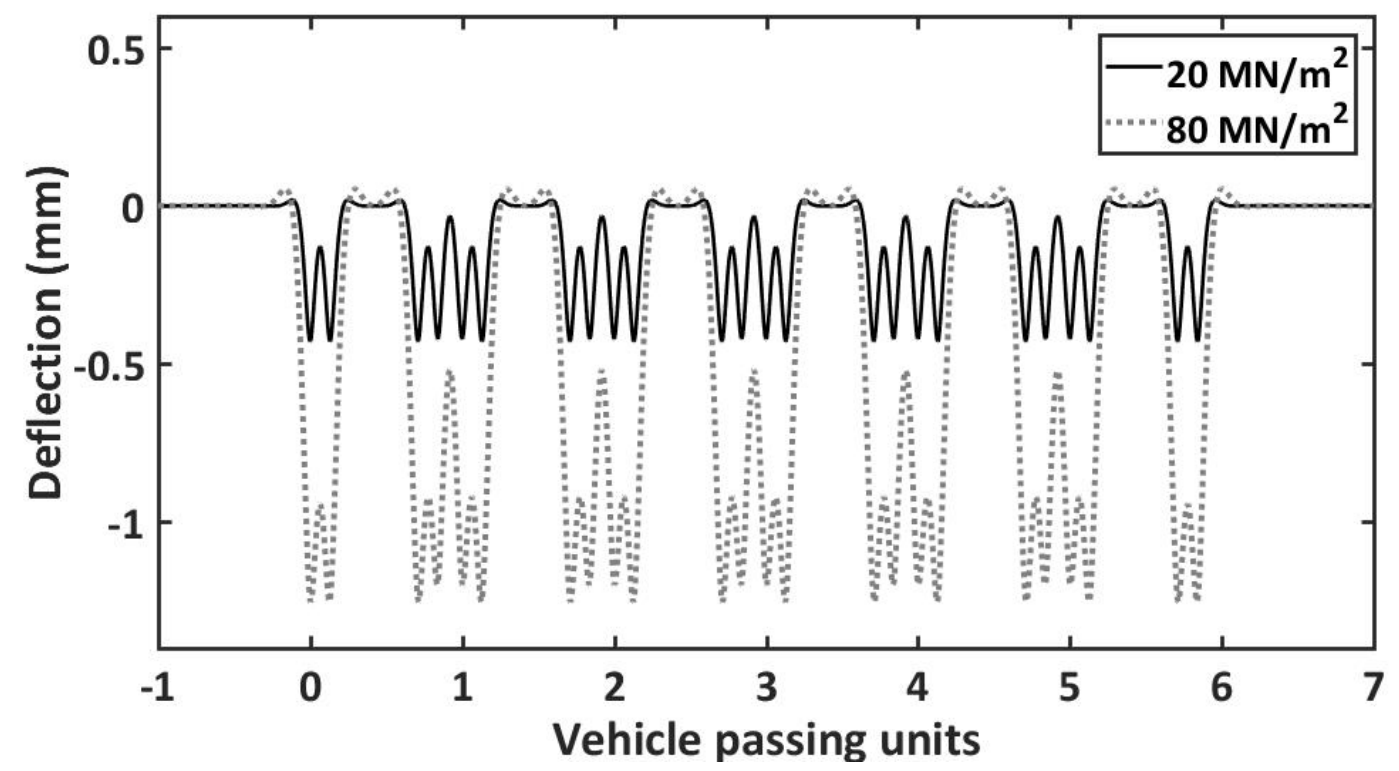

Figure 2: Illustrative time deflection trace for 6 car class 395 on two different support system moduli 


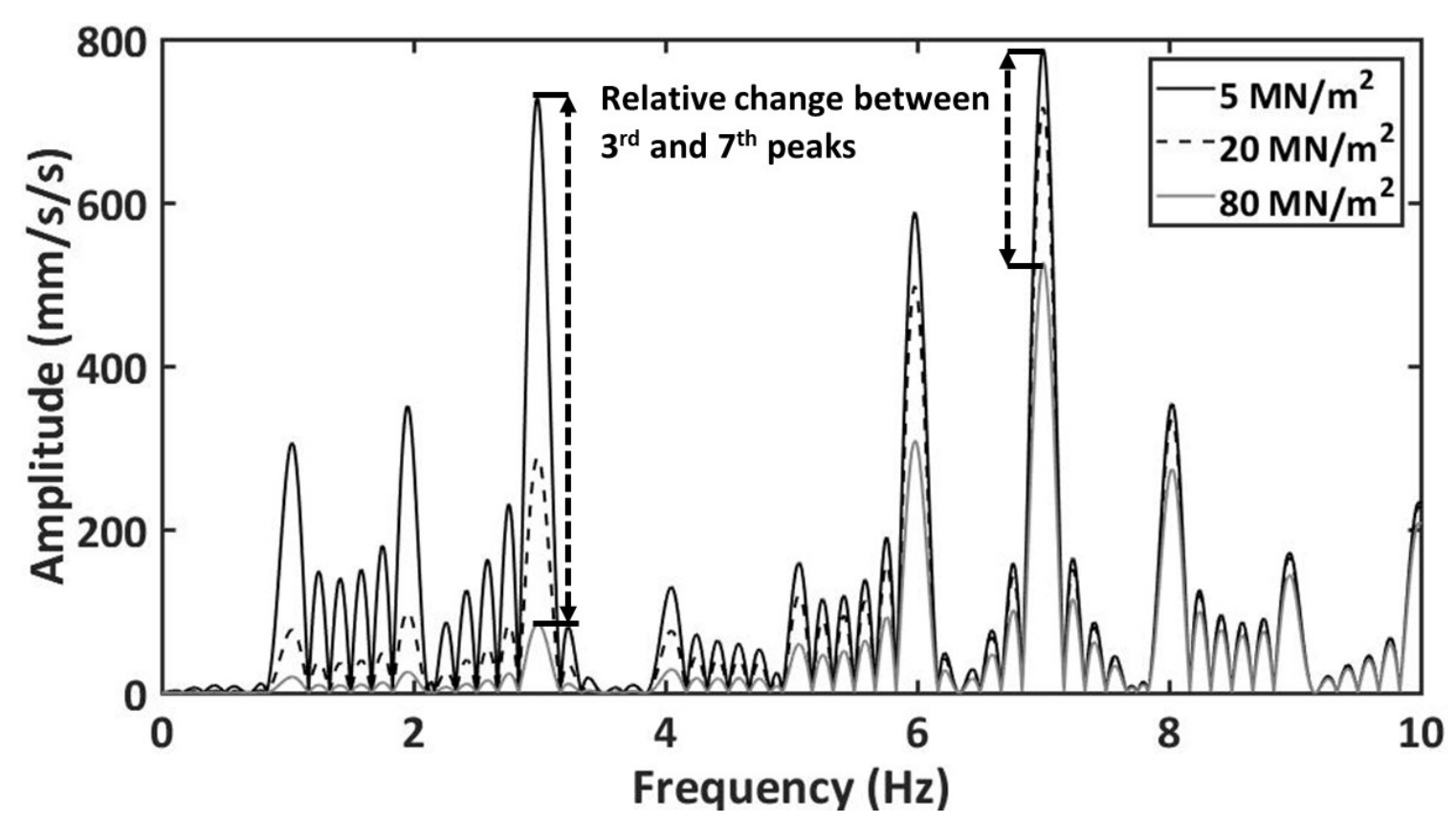

Figure 3: Illustrative acceleration spectra for 6 vehicle class 395

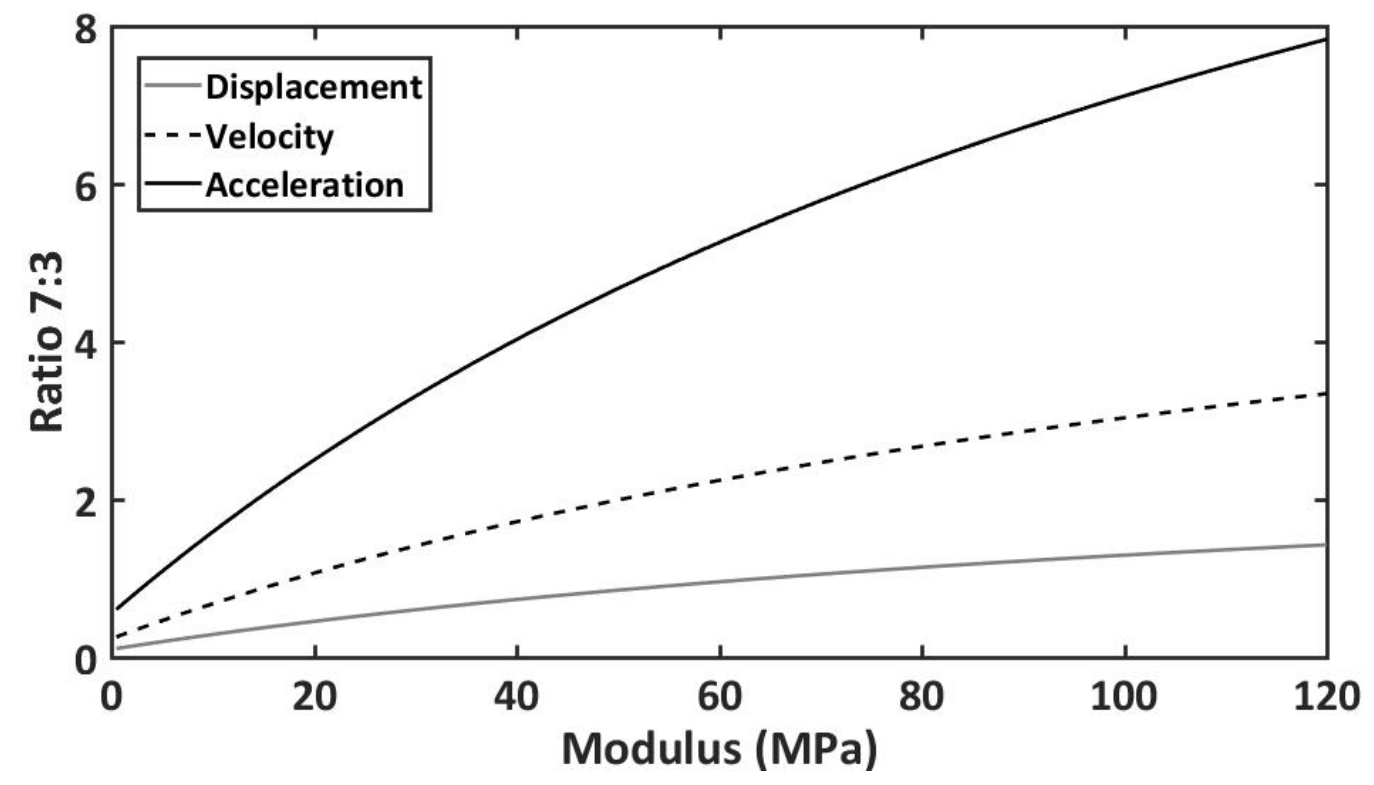

Figure 4: Ratio of the magnitudes of the 3rd and 7th harmonic peaks in frequency spectra vs track system support modulus 


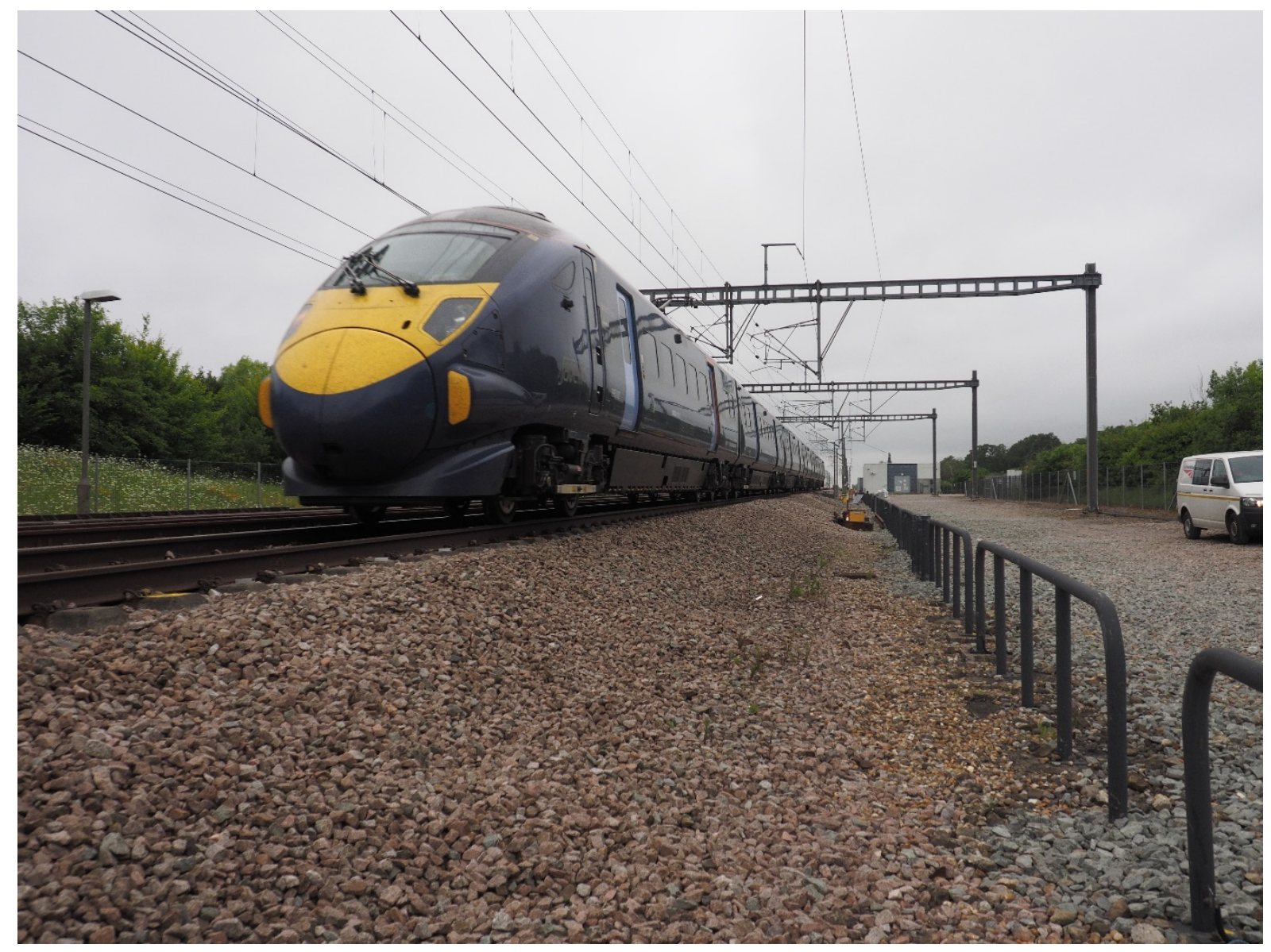

Figure 5: A class 395 passing through the site
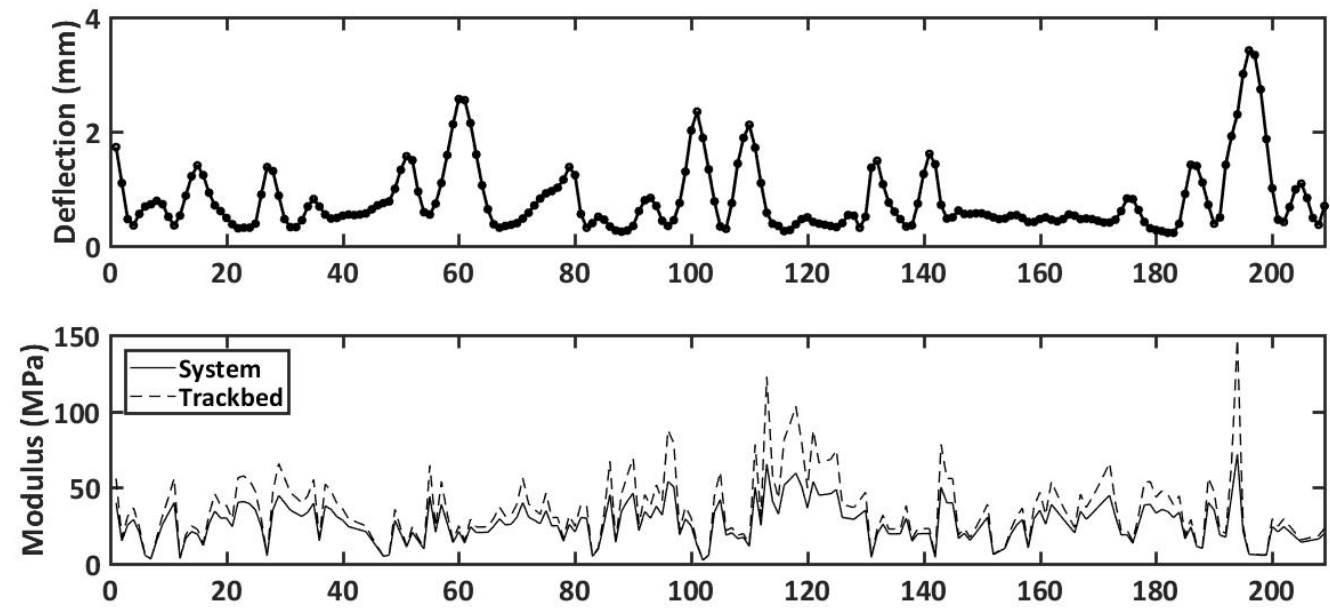

Figure 6: Average of 12 trains (a) sleeper deflections and (b) System modulus and trackbed modulus (assuming pad stiffness of $84 \mathrm{MN} / \mathrm{m}$ and $0.6 \mathrm{~m}$ sleeper spacing) 


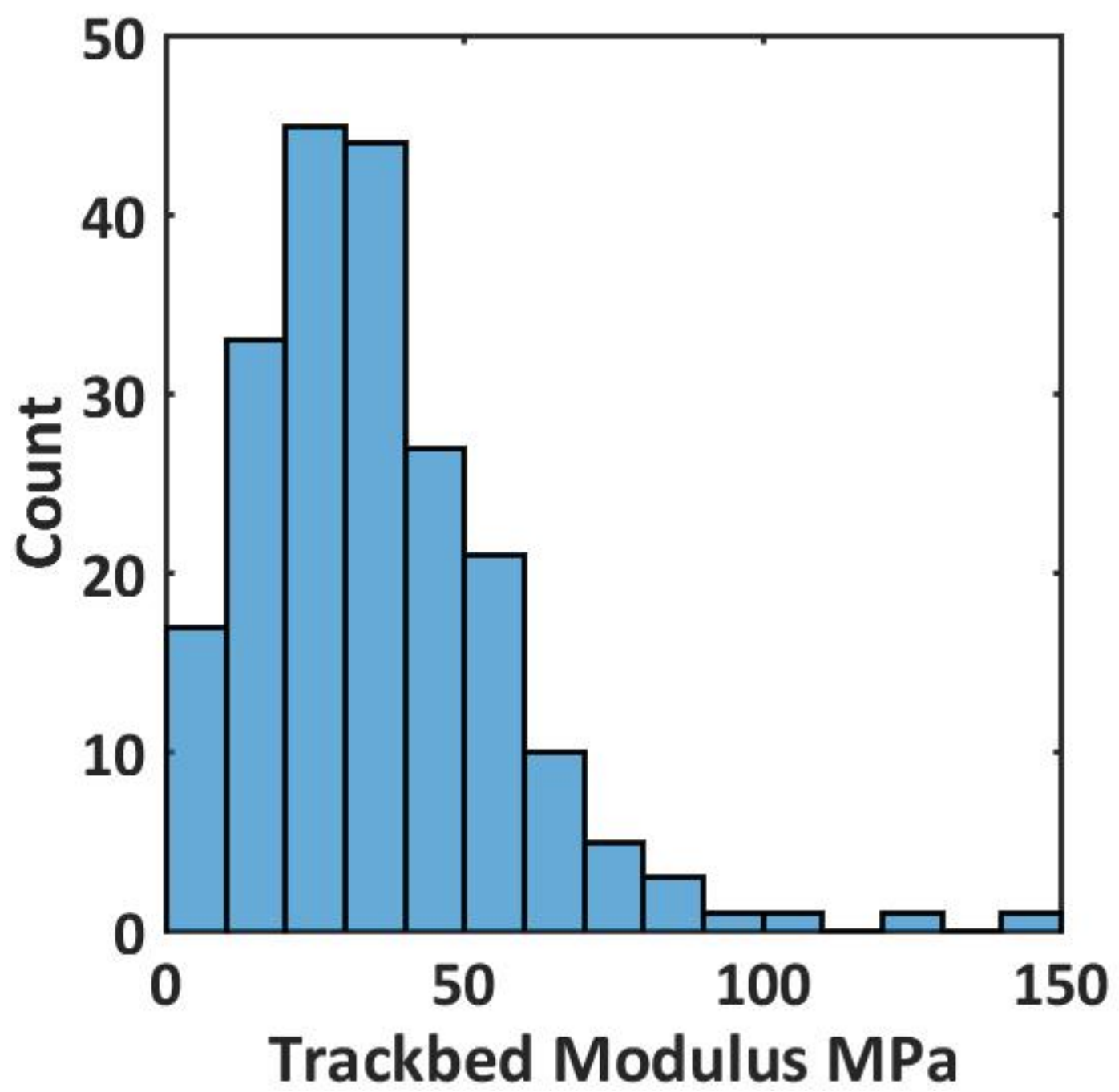

Figure 7: Histogram of trackbed modulus
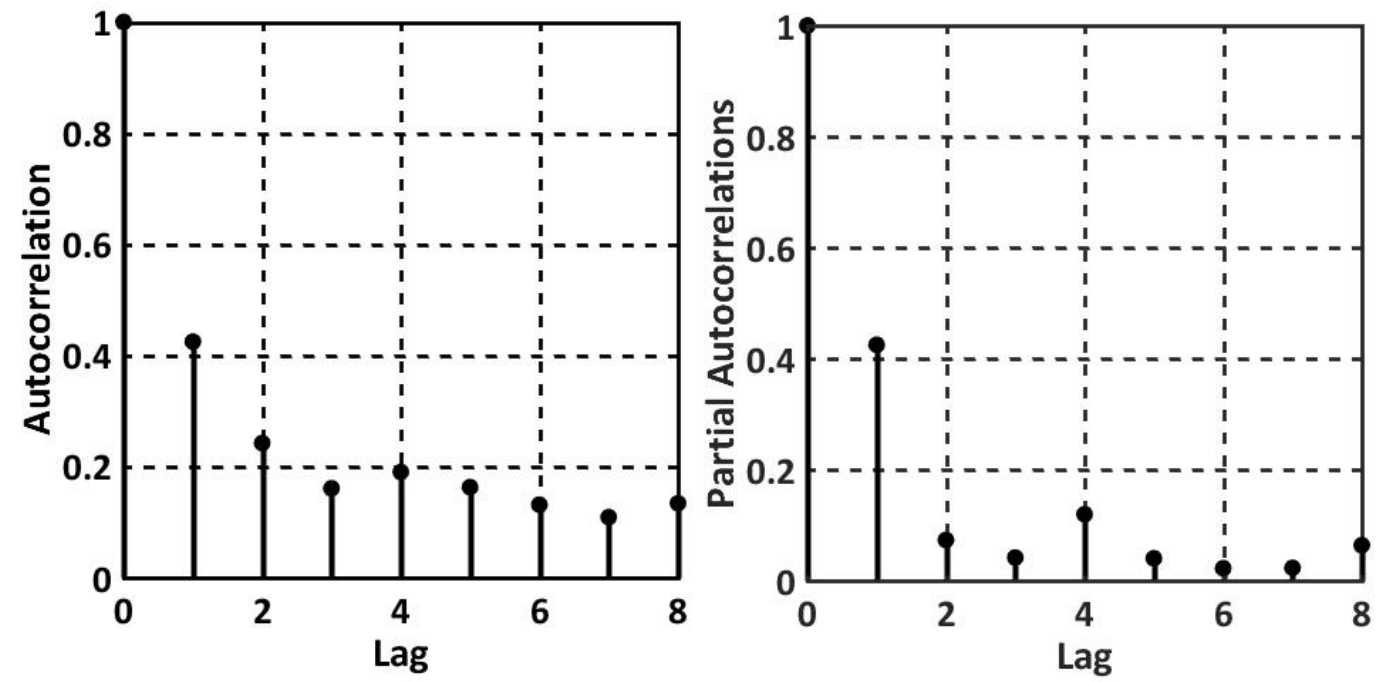

Figure 8 Auto-correlate and partial auto-correlate functions for measured trackbed moduli 


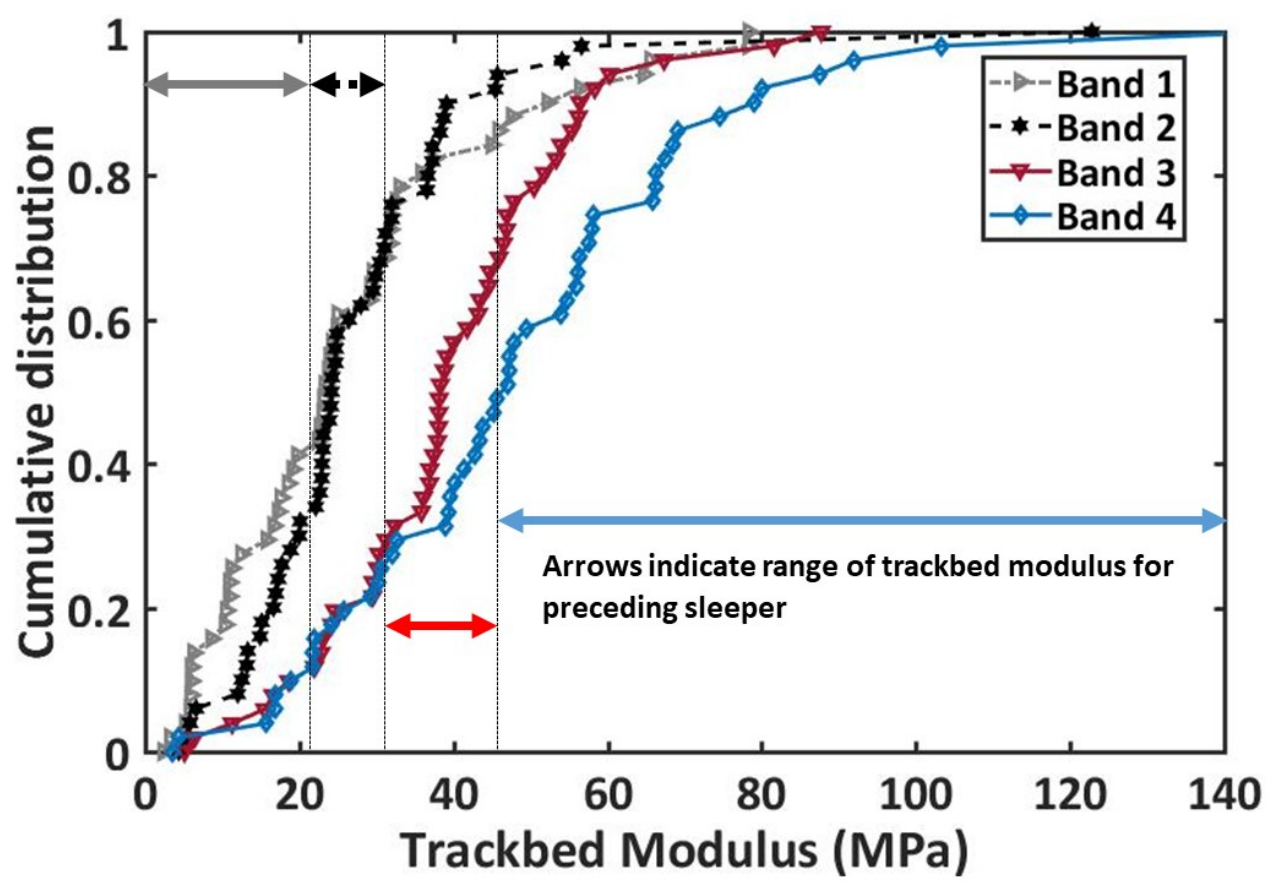

Figure 9: Cumulative distributions of trackbed modulus for the current sleeper by band for the preceding sleeper

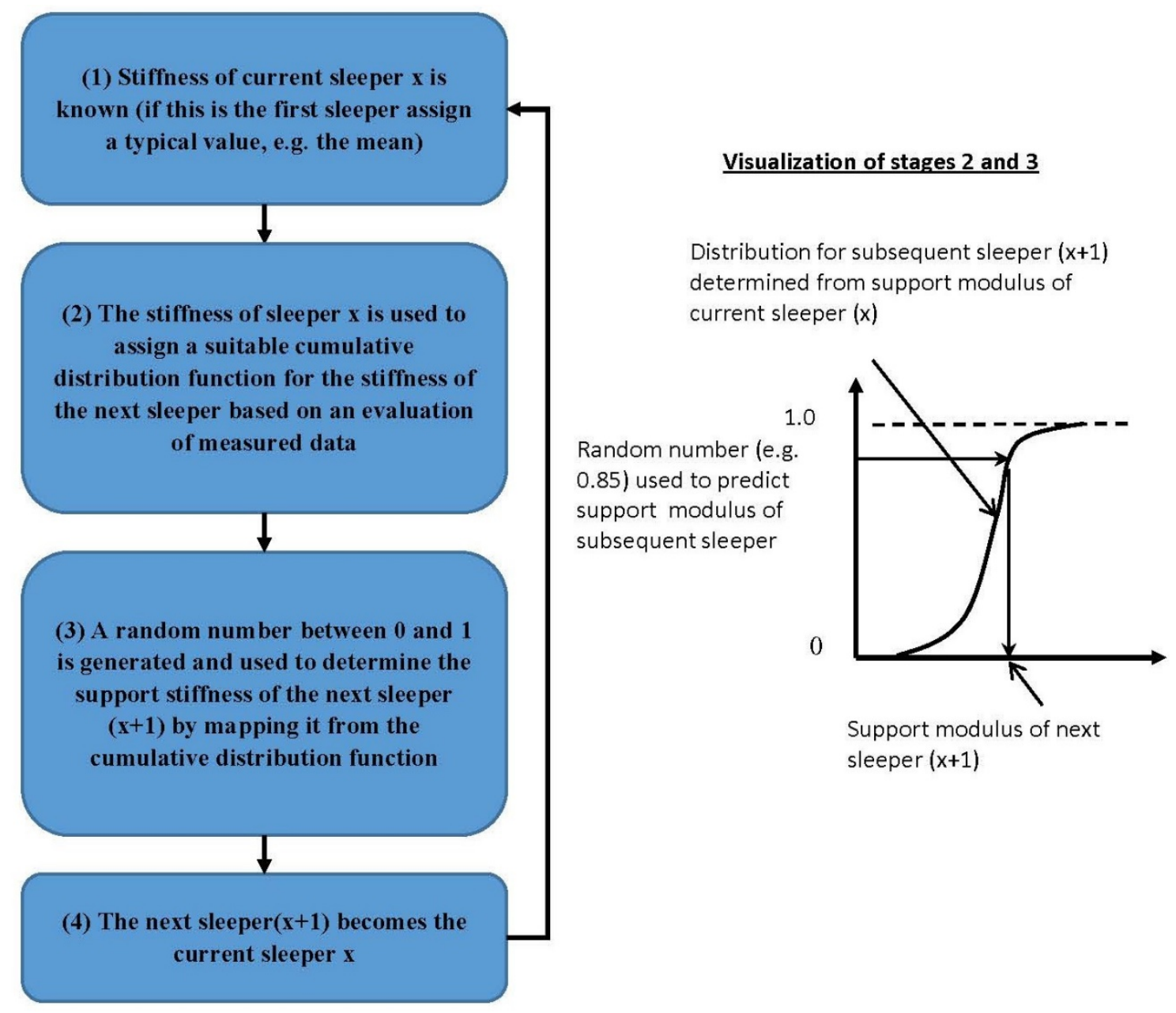

Figure 10: Markov framework application for stochastic prediction of track stiffness 

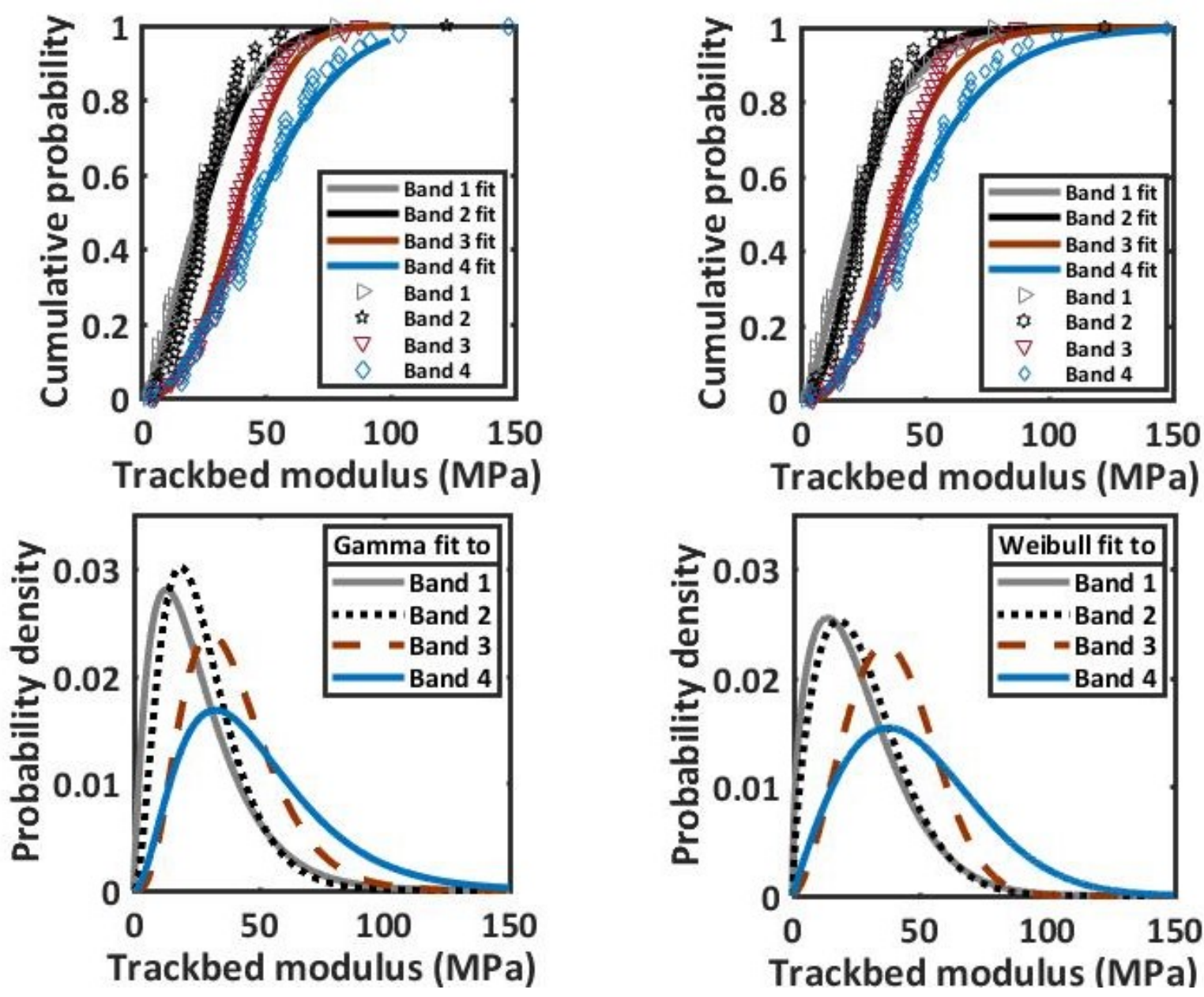

Figure 11: Functions for four bands selected (a) Weibull CDF (b) Gamma CDF (c) Weibull PDF (d) Gamma PDF
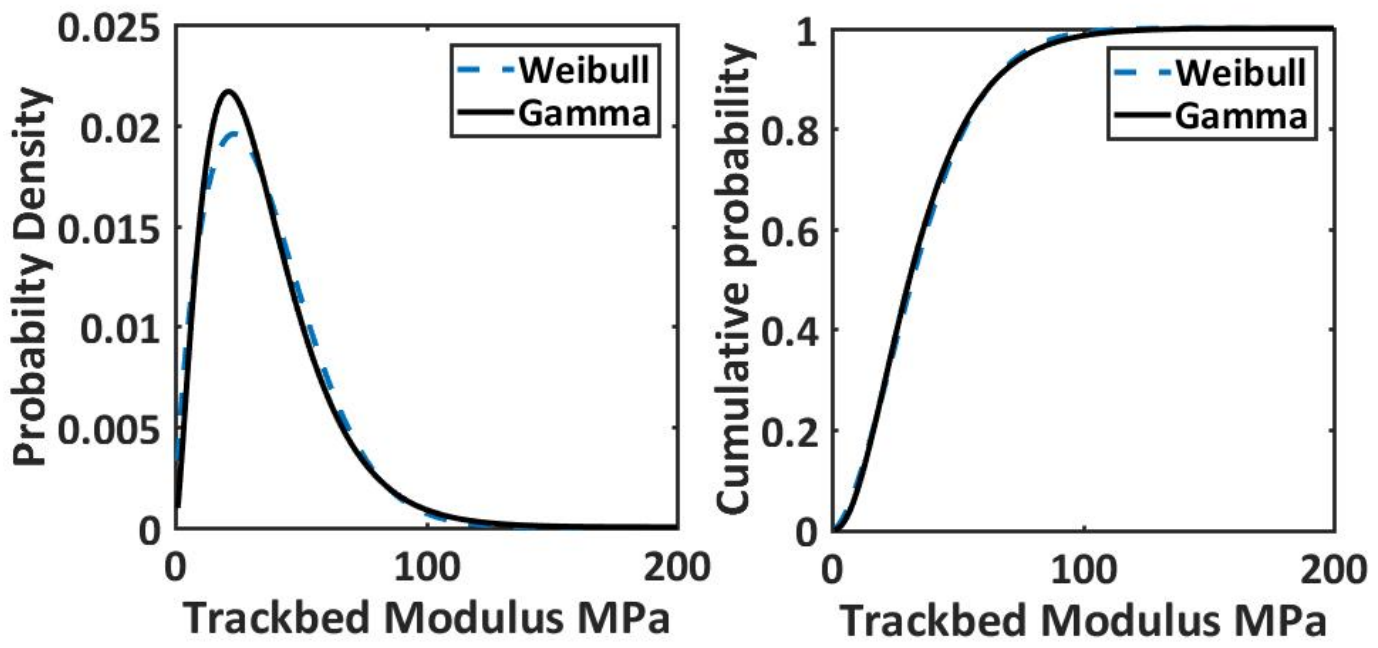

Figure 12: Probability density and cumulative distribution functions for Weibull and Gamma fits 


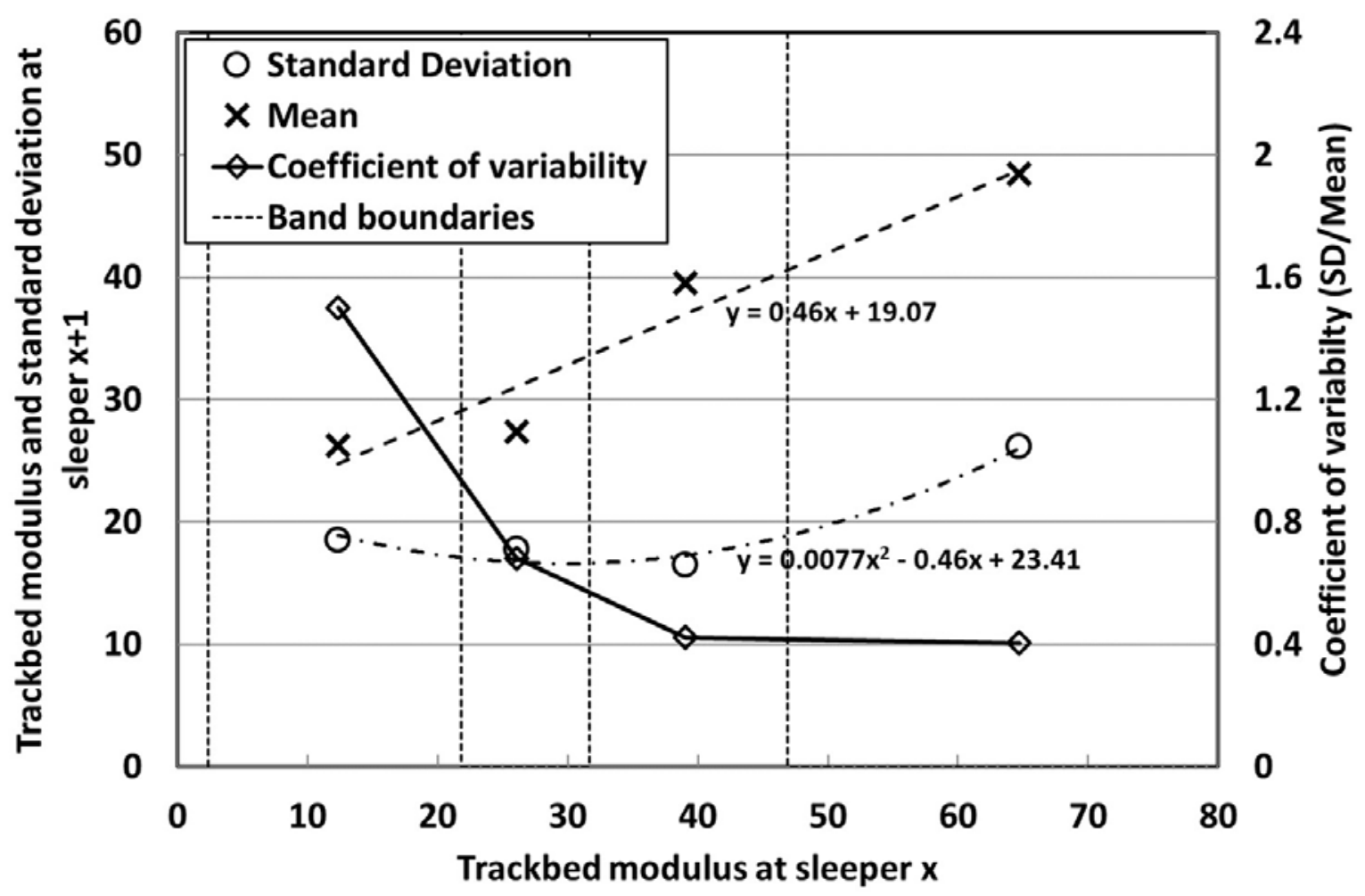

Figure 13: Relationships between mean, standard deviation and coefficient of variability of the trackbed modulus for the preceding and current sleeper from banding analysis

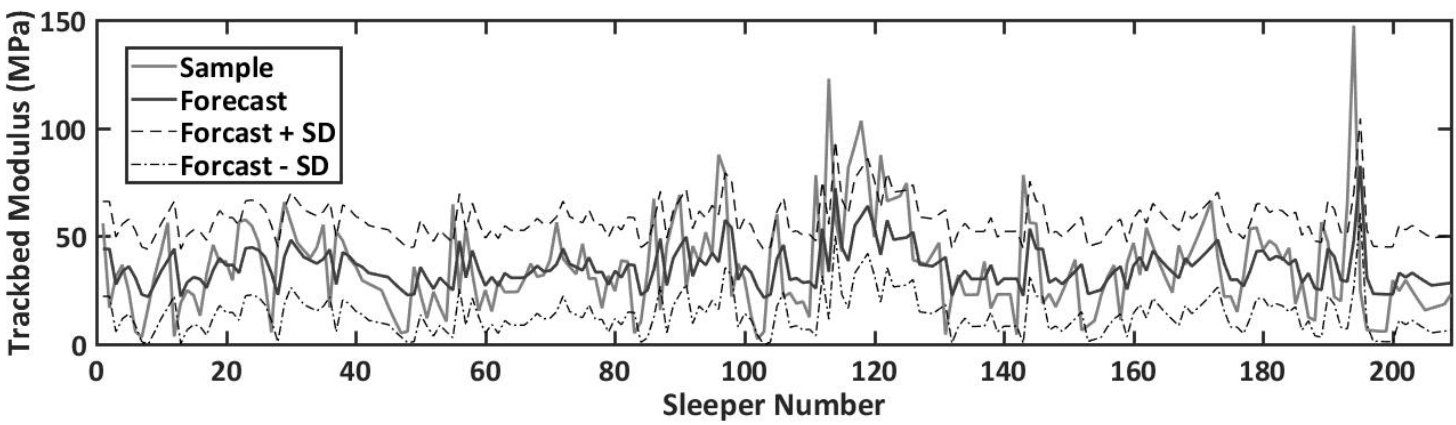

Figure 14: sample sd from measured sample and forcast mean for next sleeper 


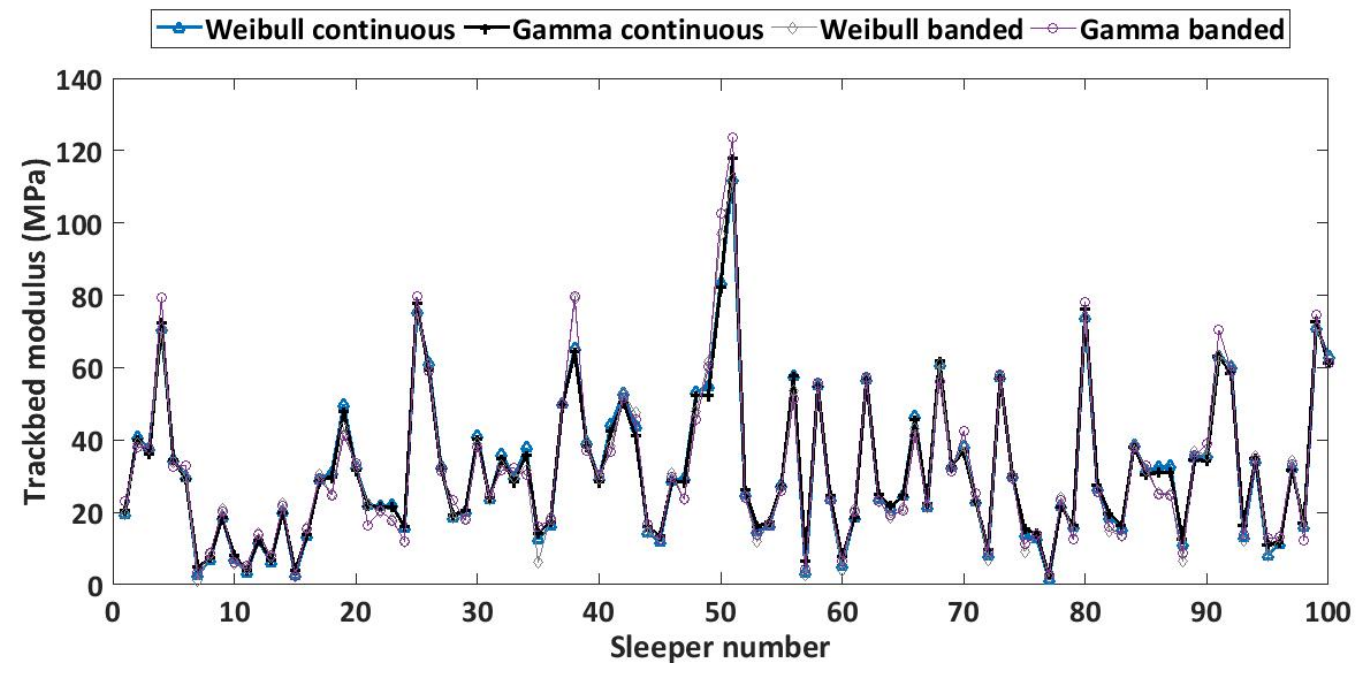

Figure 15: Simulation results using common random seed for banded and continuous distributions for the first 100 sleepers

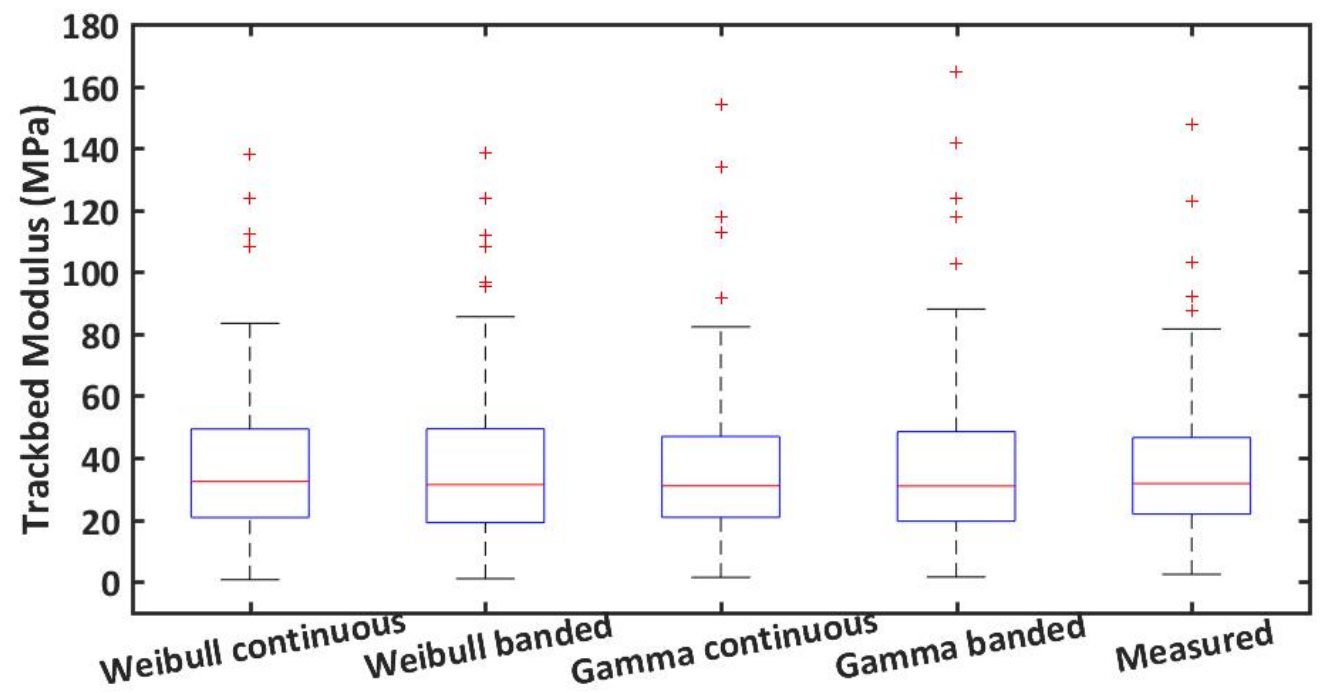




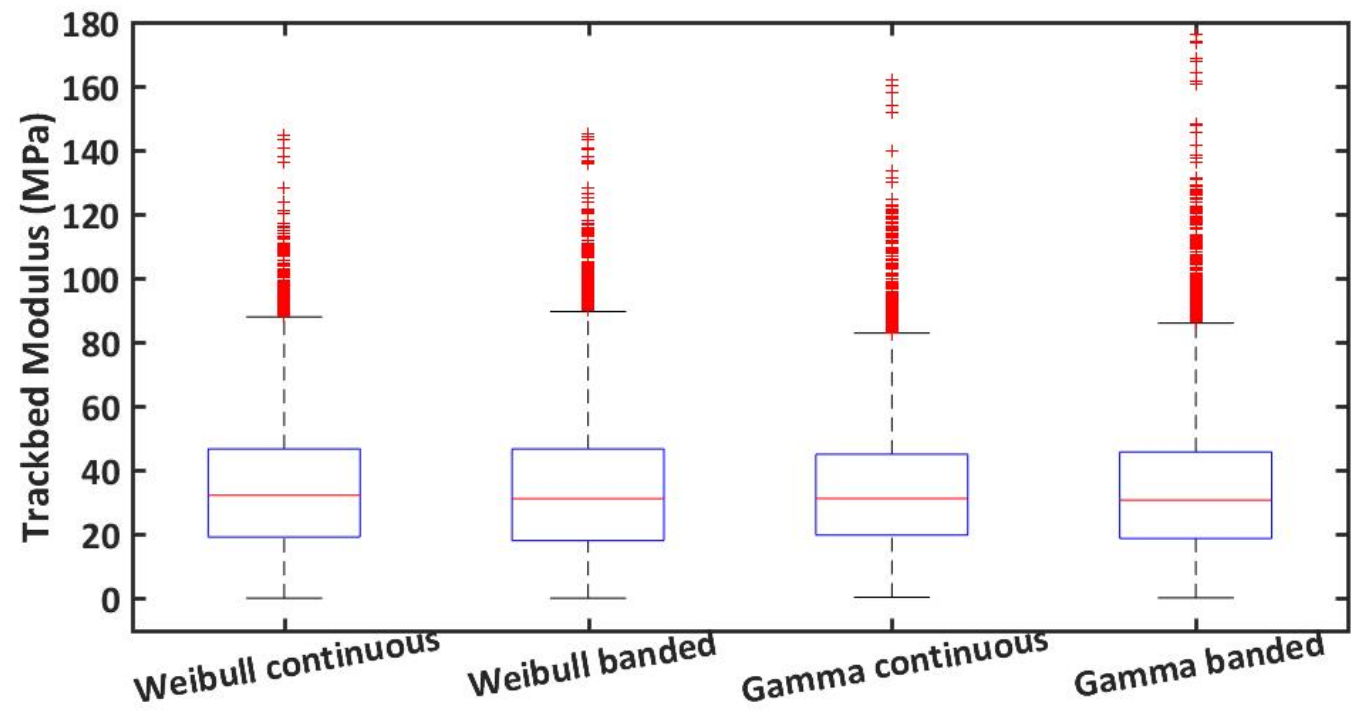

Figure 16: Boxplots for simulations and measured results for (a) the first 209 sleepers (b) 10,000 sleepers 